\title{
Higher Education in Distance Form as a Type of Educational Services: Sociological Analysis
}

\author{
Kulikova O.A. ${ }^{*}$ Komarova A.A. Kolosova O.A.
}

\author{
State University of Management Moscow, Russia 109542 \\ *Corresponding author.Email: kilka2002@yandex.ru
}

\begin{abstract}
The article considers distance learning as a universal humanistic form based on the use of a wide range of traditional, new information and telecommunications technologies, and technical means that create unique conditions for the student. Such as the free choice of educational disciplines that meet the standards, dialogue exchange with the teacher, and the learning process does not depend on the location of the student in space and time. Modern distance education technologies (DOT) offer real prospects for improving the quality of knowledge and efficiency of the educational process, for solving various social problems associated with the functioning of the Institute of education. The systematic approach made it possible to consider distance learning as a kind of integrity in the diversity of its internal and external relations.
\end{abstract}

Keywords: education, training, distance learning, educational services, student youth

\section{INTRODUCTION}

Modern society is characterized by a new view of education, which changes the functional role of the education system and gives it the character of an integrative social institution. Changes in modern societies, respectively, in the higher education system are dictated by three main factors:

- globalization

- development of information society

- $\quad$ increasing the knowledge intensity and technical and technological segment in national economies.

It is highlighted new trends in the development of modern education in the scientific literature, namely:

1) globalization of educational systems;

2) informatization and virtualization of the educational process;

3) development of innovative technologies in education;

4) commercialization of education systems.

These trends have a direct impact on the education system and set the vectors of its development.

There is a new model of acquisition of knowledge that combines high specialization with innovation or creativity [3] Evidence of the formation of a new type of economy is the development of global innovative technology parks, in particular, the SKOLKOVO innovation center, and the SKOLKOVO business school. The processes of globalization of all spheres of public life make the realization of the problem of continuous education of the population a vital necessity.

Distance learning is a universal humanistic form of education based on the use of a wide range of traditional, new information and telecommunications technologies and technical means that create conditions for the student to freely choose educational disciplines that meet the standards, dialogue with the teacher, while the learning process does not depend on the location of the student in space and time.

Distance learning becomes the optimal form of advanced training and professional retraining, in the conditions of formation of the system of continuous education and professional development.

Changes in the internal paradigm of higher education are occured, new models, guidelines, and new forms of knowledge appear in higher education under the influence of globalization challenges. One of these challenges is the global economic crisis and the accompanying shortage of resources for national education systems. The second challenge is the emergence of a crisis in the information society, the essence of which was the discrepancy and imbalance of a huge amount of information produced by mankind and the part of which was actually used in the activities of people. The third challenge is the environmental crisis caused by industrial production. These contradictions of the industrial world could not be resolved within the existing educational paradigm [12], which gave impetus to following changes in the higher education system. There was a transition from the knowledge-based to the competence-based paradigm of education. According to the creators of the concept of the information society, the economic and social functions of capital are converted into information (in particular, scientific and educational) structures; and the Central figure of post-industrial society becomes a specialist with certain knowledge and skills [12]. Due to the fact that role of the information technologies is the main role, in the conditions, in accordance with which this activity must be 
performed, it is not possible without support of the information technologies (both technological aspects, and in the sphere of application of these aspects) [8]. As a result, the University becomes the center of social organization of society.

\subsection{Related Work}

Let's consider the experience of distance education in Russia and abroad.

\subsubsection{Advantages and disadvantages of distance education as a type of educational services}

Every year, more and more educational institutions offer distance higher education. Today, this educational field is not only developing at a great speed, but also increasing its scale every day. The main advantage of distance education is the ability to get knowledge without depending of the actual place of residence of the student. Distance education is ideal for those who want to get new knowledge, but for some reason can't attend full-time classes. Getting a higher education means expanding your professional opportunities and creating a basis for successful career growth. Distance education provides a number of advantages not only for students. There are a lot of opportunities for an educational institution that provides such a service. First, there is an increase in the competitiveness of the University by reducing the cost of tuition fees, it gives a significant competitive advantage in the current crisis. Secondly, there is no need to maintain a large number of educational facilities, the problem of replacing sick teachers is eliminated, and the permanent expenses of the University are reduced due to the possibility of increasing the number of students. Third, the University providing electronic educational resources needs less budget funds from the state, in comparison with full-time training, since it requires fewer personnel involved in the organization of the educational process, fewer training and support facilities are used for conducting classes, and costs are reduced with the transition from paper to electronic media.

The use of electronic educational resources, i.e. distance learning, provides the following opportunities for students: - $\quad$ study at any time and in any place where there is a computer with Internet access. This is especially important for students who are unable to leave their home for health or other reasons;

- implement an individual curriculum. In particular, you can independently adjust the pace of studying subjects;

- eliminate the problem of purchasing training materials and manuals;

- $\quad$ reduce the cost of training in comparison with traditional forms.
Distance learning offers the following prospects for educational institutions:

- attracting the best teachers regardless of their place of residence, that is especially important for educational institutions located far from regional centers. Thus, local universities can successfully compete with the capital's educational organizations;

- $\quad$ increasing the number of students;

- the solution of many technical problems related to the maintenance of a large number of classrooms, preparation of curricula, replacement of sick teachers.

However, education using electronic educational resources has a number of negative aspects:

- $\quad$ lack of face-to-face communication between the student and the teacher, that be an individual approach;

- the need for the student to have the ability to strict self-discipline, the dependence of the learning result on the degree of independence of the student;

- lack of practical training;

- emphasis on the development of written skills and lack of oral presentation skills.

At the same time, we believe that learning through electronic educational resources will take up more and more space in modern society. Largely the intensity of this process will be consistent with the speed of development of technologies that can provide a realistic virtual space.

\subsubsection{Global trends using electronic educational resources}

Distance education is developing with incredible speed and success not only in Russia. The use of electronic educational resources is becoming more popular every day in educational institutions in various countries taking into account the global trends in the formation of information communities and the interest in including States in this process that need to support the society's desire for progress [5]._The degree of involvement of educational institutions in different countries in the use of distance learning differs. The use of distance learning is most popular in the United States - $16.8 \%$, second place is taken by China- $14.2 \%$, third place in Russia- $13.9 \%$, fourth place is taken by India-13.3\% [9]._Thus, despite the fact that Russia is a modern, dynamically developing country, in terms of the introduction of electronic educational resources in education, it occupies only the 3rd place, significantly lagging behind the United States. Distance education is developing most actively in the United States. The University of Washington (UW) is one of the leading universities in the United States in the distance learning program. The Distance learning program was created in 1912. The creation of the Open University of Great Britain (OUofGB) in 1969 had a huge impact on the development of the distance education system. Currently, 200 thousand students from different countries study here. The UK is ahead of the EU countries not only in terms of the overall level of Informatization, but also in terms of the implementation of distance learning systems. 
Training is carried out in such a way that face-to-face classes are not necessary, all training can take place at a distance at the United Kingdom Open University. Distance learning at the University of New England in Australia has a different learning model. The proportion of "full-time" students is significantly higher than the proportion of "distance" students in this organization. Distance learning is not "profitable" from a commercial point of view, and the bet is on an educational experiment in such universities.

The mixed model involves the integration of various forms, where full-time courses run in parallel with distance courses. An example of such courses is the integrated courses at Massey University in New Zealand.

In recent decades, distance learning has been actively developing not only in North America and Europe, but also in South-East Asia. Today, there are 70 universities in Asia, including 7 of the 11 largest universities in the world, each with more than 100,000 students. The blurring of borders between Asian States and other unique social formations in Asia has led to active experimentation in the field of education and an increase in the number of distance learning programs and universities. They develop unique mixed programs here that effectively synthesize independent learning with virtual and traditional learning. In Thailand, the idea of creating a University that uses distance learning technologies originated in the 70s of the XX century. Currently, the State Thai Open University (STOU) has 6 faculties (Economics, management, information technology, health, education, and agriculture) that provide bachelor's and master's degree programs. An interesting experience in the development of distance learning in higher education has been accumulated in Malaysia, where the first virtual University in Southeast Asia was established in 1998. The Malaysian virtual University is a "hybrid" of traditional University and distance learning.

\subsubsection{Problems of education in Russia.}

Currently, potential students face a number of problems when receiving professional education in Russia.

The first of them is the problem of large territories with an uneven distribution of population. Although the population is distributed throughout the country, most high-level educational institutions are concentrated in the Central part. And moving to another city is often impossible due to a number of reasons, primarily financial. There is also a need to improve the education of people working in the regions, usually with families, for whom moving to another city is associated with significant difficulties.

The second problem is the time factor. Today, most modern specialists have little time left to devote to getting an education. And yet no one can do without getting new knowledge, without learning throughout life.

The third problem is finances. This mainly concerns higher education and preparation for it. The competition for budget places is high, and not everyone can afford paid tuition.
Distance education can help solve all of the above problems. Based on the name, we see that this training is "at a distance", i.e. at a distance when the teacher and the student are separated in space. Obviously, new technologies are used for presenting educational materials. Thanks to them, distance education is cheap and widely available, opening up opportunities for interaction over long distances [10]. The development of distance education was influenced by modern achievements in the field of learning technologies, mass media and communication, the rapid development and widespread use of various technical means. First of all, these are computer and information technologies, satellite communication systems, educational television, mass connection to information networks, distribution of educational software, etc. Currently, one of the priority areas of educational activities of higher education institutions in Russia is becoming additional professional education. This is due to the extremely rapid technological and scientific changes in the twenty-first century. Thus, the "education through life" paradigm becomes a priority for professionals who are focused on real professional growth. The concept of long-term socio-economic development of the Russian Federation for the period until 2020 in section 4 "Development of education" provides for the formation of a system of continuous education "through the implementation of a national qualifications framework, certification system of qualifications, modular programs," the key element of which is professional development and professional retraining that will "maximize human potential and create conditions for selfrealization of citizens throughout life" [4].

The main goal of additional professional education can be defined as a purposeful continuous improvement of professional knowledge of citizens who already have professional education in their $\mathrm{CV}$, updating their professional qualifications and readiness to perform new types of professional activities [4]. The importance of professional development is also reflected in the professional standards: the time limits for professional development have been changed. Now, instead of once every five years, specialists need to take such courses every three years or even every year for some activities. In this regard, Russian higher education must increasingly respond to the rapidly changing demands of the time.

The analysis of the scientific literature on the studied problem shows that distance learning technologies are the basis for the organization of modern additional professional education [2].

\subsubsection{Features of distance learning components in the organization of the educational process}

Further, we consider it necessary to analyze the didactic possibilities of distance learning components in the organization of the educational process of the system of additional professional education. In modern didactics, there is no common opinion about the concept of a 
teaching method. U. K. Babansky defines the method of teaching as a way of orderly interaction between the activities of the teacher and students, aimed at solving the problems of education. I. F. Kharlamov believes that the teaching method is a way of teaching the teacher and organizing educational and cognitive activities of students to solve various didactic tasks [6]. In our opinion, the most comprehensive definition of the teaching method that we will adhere to is formulated by A.V. Slastenin: "methods of implementing a holistic pedagogical process should be understood as ways of professional interaction between the teacher and students in order to solve educational tasks" [13].

The analysis of training methods in the organization of additional professional education will be carried out using the classification of training methods developed by M. N. Skatkin and I. Ya. Lerner. In this classification, the main feature is highlighted as the nature of the cognitive activity of students on the learning of the studied material.

The information-receptive method assumes that the transfer of educational information is made using various didactic tools, including textbooks in electronic form. This method is one of the most economical ways to transmit information and involves a large amount of independent work of students. This feature of the information-receptive method makes it very useful when organizing the educational process in the distance learning system. The essence of this method of training is based on the algorithmic nature of the student's activity - it is the performance of various exercises and tasks similar to those presented in the recommendations, guidelines, which provides the formation of practical skills. Therefore, this method is also appropriate in the practice of distance learning.

Pedagogical practice also uses methods of problem presentation and partially-search (heuristic) methods. The activity of the student in the first case is not only in the perception and understanding of scientific conclusions, but also in tracking the logic of arguments. The thinking process becomes productive under the guidance of the teacher when using the part-search method. The main purpose of the method is systematic preparation of students for independent solution of various problems in real practice. Both of these methods involve direct interaction between the teacher and the student, which is quite difficult in the conditions of distance learning.

It is very promising to use the research method in the organization of distance learning, which involves the formulation of problems and the formulation of tasks by students. First, the teacher provides methodological recommendations on rational ways to solve the problem, then students independently investigate sources on this problem, make observations and perform various search actions. Educational activities are inextricably linked to scientific research with this method. A research character in students' educational activities develops their initiative and independence. There are various organizational forms of training: lectures, practical classes (seminars, workshops), independent work, and so on in University practice, regardless of the type of education. The training process is accompanied and completed at each stage of training by various types of control. The specifics of distance learning make it possible to conduct lectures in real time, or in extended time (off-line) using conferences. Video lectures can be broadcast via telecommunications to educational centers of additional professional education, but given the specifics of distance learning (for example, the difference in time zones), such types of lectures should be used only as an extreme measure. The undeniable advantage of this type of lectures is the ability to study the lecture material at any convenient time, as well as the ability to repeatedly listen to the most difficult to digest material. It is especially recommended to conduct remote lectures using text materials on the topic with expanded content at the expense of additional material and further consultation of students with the teacher by e-mail.

Practicums plays a crucial role in developing the skills and abilities to apply the acquired knowledge. Conducting practicums requires a deep methodological study from the teacher as well as conducting lectures. Conducting a laboratory workshop has a great specificity, which takes into account the peculiarities of the subject area being studied. Therefore, it is necessary to use computer-based training systems when conducting a laboratory workshop, which can ensure the development of practical skills [11, 12]. The control of knowledge, abilities and skills acquired in the course of training has a stimulating effect. Control measures establish feedback from the student to the teacher. There is no real face-to-face contact between teachers and students in the conditions of distance learning when organizing additional professional education. Therefore, it is important to establish feedback in the form of input, current and final control, which makes it possible to control the learning process and subsequently plan the learning process taking into account the individual characteristics of students.

Independent work of students in distance learning is leading, but at the same time organically combines other forms of the educational process.

The focus is on providing students with educational materials, training tools, and solving the problem of technical support for the education process when organizing independent work. A. A. Andreev identified the following groups of them [1] analyzing the means of training, taking into account their specific features in the conditions of distance learning: paper publications, online teaching tutorial, computer training programs, didactic audio and video materials, laboratory remote workshops. The use of distance learning tools in the educational process of additional professional education needs to be systematic and technological, which significantly affects the increase in the level of efficiency of educational activities.

The analysis of the components of distance learning illustrates the possibility of its usage in the educational process of additional professional education. Moreover, the use of distance learning can significantly increase the quality of educational activities by the student through the 
use of effective teaching methods, through the use of different organizational forms in learning, but requires comprehensive information and technological support and the use of integrated educational and methodological support.

\subsection{Our Contribution}

The main prerequisites and trends for the introduction of distance education in Russia, as well as prospects for the development of distance learning in higher education are considered in this article from the point of view of a systematic approach. An empirical analysis of the attitude of students to obtaining higher education in the distance form is carried out.

\subsection{Paper Structure}

The rest of the text is organized as follows. Section 2 describes methodological tools for conducting an empirical study of students' attitudes to higher education in the distance form. Section 3 presents the results of a questionnaire survey of students. Section 4 completes the work by summarizing the data and providing a direction for future research.

\section{BACKGROUND}

\subsection{Methodology of the empirical research}

An empirical study on students' attitudes to distance education was conducted in September 2019 through an electronic questionnaire using the Internet.

This information allowed for a more thorough study of the issue in order to develop more effective practical recommendations.

An additional method is a focused interview. Empirical material using this method was collected in OctoberNovember 2019.

We used the electronic questionnaire method to identify the quantitative characteristics of the phenomenon being studied, and the use of the focused interview method is necessary to verify the reliability of the results obtained and to add some qualitative characteristics.

At the first stage of the study, a research program and tools were developed (based on a preliminary theoretical analysis). Then the empirical stage of the study was implemented.

The survey of students was conducted in social networks using the online survey methodology. The topic of confidentiality and the importance of obtaining individual results was highlighted before the direct survey. The time for students to fill out questionnaires wasn't limited.
The focused interview was conducted in the building of the State University of management.

The questionnaire for students includes 27 questions, but in this article we will consider only some of the results obtained. All questions in the questionnaire are open, 3 of them are multiple-choice questions.

Processing, analysis and description of the obtained data was carried out at the last stage of the research.

The empirical object of the study using the electronic questionnaire method is Russian students. 200 respondents took part in the study.

The empirical object of the research using the focused interview method is students of the State University of management. The study was involved 28 people.

Next, let's look at the structure of the sample population for the conducted study using the electronic questionnaire method. We do not have complete data on the structure of the General population, so we cannot fully judge the representativeness of our sample. However, the gender distribution was kept according to quotas.

\subsection{The attitude of Russian student youth to obtaining higher education in the distance form.}

The first question that was asked to GUU students was: "Do You Support the introduction of distance learning programs at GUU?". This question is familiarization, so its main task is to draw the Respondent's attention to the topic under study. $65 \%$ of respondents support the introduction of programs with distance learning, $16 \%$ of respondents do not support, the remaining 19\% chose the option "I find it difficult to answer", that is, they do not have a formulated position on this issue. The second question of our questionnaire is aimed at identifying the Internet activity of respondents: "How often do You use the Internet?" The results were unambiguous: $96 \%$ of respondents constantly access the Internet from their phone or computer, and only $4 \%$ use the Internet several times a day, but for a short time. Also in our questionnaire there were variants of the answer "I use to a much lesser extent than others" and "I practically do not use the Internet", which were not chosen by any Respondent.

We can assume that students are potentially ready to enroll in distance education programs considering the result of this distribution in isolation from the following parameters, which have not yet been considered by us, which requires a significant daily (weekly) stay on the Internet. Then, we asked the following question in our questionnaire: "Do You have an idea of how distance learning takes place in higher education programs?" The vast majority of respondents $(77 \%)$ have little or no knowledge of how the educational process proceeds in distance education programs, among them $13 \%$ "have no idea" and 64\% "do not know exactly, but have some guesses". Only $23 \%$ of respondents chose the answer "Yes, I have a fairly complete idea". 
Based on this, we can conclude that in the case of opening distance learning programs in Russian universities, it is necessary to place a special emphasis on informing about the characteristics, methods, and distinctive features of training in distance higher education programs, since even with an intuitive positive attitude to such programs, in fact, in our opinion, few people decide to " buy a cat in a bag". Let's consider the question number 5 next: "do you think it is possible to get high-quality knowledge by studying at a University remotely"? A dichotomous scale was used and $58 \%$ of the respondents believe that it is possible to get quality knowledge on distance higher education programs, while $42 \%$, respectively, believe that it is impossible to get quality knowledge on such programs. We can conclude that the opinions of students are highly polarized. Next, let's look at the statistical relationship of this question with the previous one in order to find out how students' perception of the quality of knowledge provided in distance learning programs is related to students' awareness of the nature of such programs. We will use the " Pearson's agreement criterion $\chi 2$ " to implement this task. To do this, we transcoded the question No. 3: answer option "Yes, have a fairly complete picture" denoted as "full view" and the answer "do not know, but have some guesses" and "don't have the slightest idea" join in "incomplete performance, or lack of it". This operation is necessary to ensure that the theoretical frequencies in all cells are higher than or equal to 5 . We get the value of the Gamma coefficient $=0.53$ when implementing this method using the "SPSS" program, which illustrates a fairly clear relationship.

Next, you need to check whether this relationship exists in the General population. Asymptotic significance $=0.052$. $\mathrm{H} 0=$ Gamma gene $=0$. To test $\mathrm{H} 0$, we must compare the asymptotic significance with $\alpha$ equal to 0.05 . When performing elementary operations, it can be understood that the asymptotic significance slightly exceeds $\alpha$, so there is no formal relationship on the General population. However, this is due, in our opinion, to a small sample size. However, it can be concluded that students who are informed about distance education have a better opinion of it than uninformed students. Next, let's look at the question presented in the questionnaire under number 6: "for which educational programs, in Your opinion, the distance learning form is most suitable?"the most popular answer is "distance learning courses" (61\% of respondents chose It). Next in popularity are: "advanced training and retraining of specialists" (46.7\%), "pre-University training" (43.5\%). According to respondents, bachelor's and master's programs are the least suitable for distance learning: $19.6 \%$ and $21.7 \%$, respectively.

However, this is due to a small sample size in our opinion. Still we can conclud that students who are informed about distance education have a better opinion of it than uninformed students. Next, let's look at the question presented in the questionnaire under number 6: "Which educational programs the distance learning form is most suitable in Your opinion?" the most popular answer is "distance learning courses" ( $61 \%$ of respondents chose It). Next in popularity are: "professional development and retraining of specialists" (46.7\%), "pre-University training" (43.5\%). Bachelor's and master's programs are the least suitable for distance learning According to the respondents: $19.6 \%$ and $21.7 \%$, respectively.

Most likely, this is due to the fact that, according to respondents, full-fledged higher education programs should be implemented in full-time form. In addition, various training programs and courses implemented in the Internet space are widespread now, so in the minds of students they are suitable for distance learning a priori. Let's move on to the question presented in the questionnaire number 7: "What is the effectiveness of distance learning in Russian universities in Your opinion?". $10 \%$ of Respondents rate the effectiveness of distance learning in Russia as "low", 30\% - "below average", 40\% - "low", 15\% - "below average", 3\%"high", $2 \%$ of respondents chose the option "I find it difficult to answer. Here is an example of students' attitude to stereotypical statements. For example, $75 \%$ of respondents agreed with the statement "No new technologies can compare with live communication with a teacher". $76 \%$ of students agreed with the statement "one of the significant disadvantages of distance learning is minimal interaction between students". $83 \%$ of students agreed that distance learning develops self-reliance and self-discipline skills. Based on the analysis of a number of similar questions, we can conclude that the attitude of students to distance education is quite twofold, since they agree with both positive and negative judgments about distance higher education. We would like to make another conditional analysis: if the percentage of students who agree on a particular judgment is more than $70 \%$, then we will call this agreement "strongly pronounced". Thus, only 1 out of 3 positive statements about distance education was distinguished by a "strongly pronounced" agreement of students, and 3 out of 4 was distinguished by negative ones. The vast majority of respondents $(85 \%)$ do not acknowledge the future of higher education as a substitute for distance learning of other forms. The Research shows that this opinion is correct at the current stage of historical and technological development, since many modern teaching methods have a low ability to adapt from the traditional form to the distance one. However, the study managed to get interesting data: the vast majority of respondents, among those who took courses on online platforms believe that you can get quality knowledge by studying at a University distantly, and the majority of respondents among those who did not take such courses believe that any distance education can't give a student 
management of the State University of Management. City of Moscow

\section{REFERENCES}

[1] Andreev A. A. Didactic foundations of distance learning in higher educational institutions: dis doctor of pedagogy sciences'. - Moscow, 1999. - $289 \mathrm{p}$.

[2] Baidenko V. I. the Bologna process: European and national qualification structures. (Book-Appendix 2) / Pod nauch. edited by Dr. ice. of Sciences, Professor V. I. Baydenko. - Moscow: Research center for quality problems of training specialists, 2009.

[3] Bell D. the Coming post-industrial society. Experience in social forecasting. Translated from English. Ed. 2nd, ISPR. and extra-M.: Academia, 2004.

[4] Domrachev V. G. Distance learning: opportunities and prospects / / Higher education in Russia. - 1994. No. 3. - P. 10-12.

[5] Drucker P. post-Capitalist society / / New postindustrial wave in the West. The anthology / Under the editorship of V. L. Inozemtsev. - Moscow: Academia, 1999.

[6] Frolov D. A., Vishtak N. M., Miloserdov A. A. Software implementation of an interactive computer training system for training personnel of nuclear power plants / / Young scientist. - 2015. - No. 22-5 (102). - Pp. 26-28.

[7] Goreva O. M., Barbakov O. M. Distance form of higher education: realities and prospects. Tyumen: Vector Buk, 2007-159 p.

[8] Komarova A., Tsvetkova L., Kozlovskaya S., Pronkin N. Organisational Educational Systems and Intelligence Business Systems in entrepreneurship education. Journal of entrepreneurial education. 2019. Vol. 22. No. 5. Pp. 445.

[9] Kulagina Yu. a. Preparation of future teachers of professional training for the use of remote educational technologies: dis. . cand. PED. Sciences: 13.00.08/ Togliatti state University. - Penza, 2013.

[10] Lukinykh T. N., Mozhaeva G. V. Information revolutions and their role in the development of society. electron. journal. Humanitarian Informatics: Vol. 3. URL: $\quad$ http://huminf.tsu.ru/e-jurnal/ magazine/3/luk_moz.htm (accessed 30.02.2020).
The study was conducted by employees of the Department of sociology and psychology of 
[11] Vishtak O. V., Shtyrova I. A. Criteria for evaluating the activities of the University center for additional education / / Fundamental research. - 2013. No. 4-3. - Pp. 555-559.

[12] Vostroknutov E. V., Volkov S. N., Adamsky S. S., Mokievskaya N. E., Zaitsev V. A. Implementation of educational remote multimedia Internet projects / / XXI century: results of the past and problems of the present plus. - 2014. - No. 4. - Pp. 66-70. DOI: https://doi.org/10.1007/3-540-11494-7_22

[13] Zinder E. Z. Systematic approach to the formation of complex educational information systems based on standards / E. Z. Zinder / / Foreign languages in distance learning. Materials of the III international scientific and practical conference. - Thom. 1. - Perm state technical University press. - 2009. 